S. Santos-Assunçao, V. Perez-Gracia, V. Salinas, O. Caselles, R. GonzalezDrigo, L.G. Pujades, N. Lantada. 2016. GPR backscattering intensity analysis applied to detect paleochannels and infilled streams for seismic nanozonation in urban environments. IEEE Journal of Selected Topics in Applied Earth Observations and Remote Sensing, 9(1), 167 - 177 DOI: 10.1109/JSTARS.2015.2466235

\title{
GPR backscattering intensity analysis applied to detect paleochannels and infilled streams for seismic nanozonation in urban environments
}

S. Santos-Assunçao(1), V. Perez-Gracia(2), V. Salinas(3), O. Caselles(3), R. Gonzalez-Drigo(2), L.G. Pujades (3), N. Lantada (3)

(1) Murphy Surveys, Kilcullen, Co. Kildare, Ireland; +353 45484 052; sassuncao@murphysurveys.ie

(2) Department of Strength of Materials and Structural Engineering (RMEE). EUETIB, Polytechnic University of Catalonia, Barcelona-Tech. C/ Urgell 187, 08036-Barcelona, Spain (Spain), sonia.assuncao@upc.edu; vega.perez@upc.edu, jose.ramon.gonzalez@upc.edu

(3) Dpt. Ingeniería del Terreno, Cartográfica y Geofísica, Universidad Politécnica de Cataluña, C/ Jordi Girona 1-3, 08034 Barcelona, (Spain), victor.salinas@upc.edu; oriol.caselles@upc.edu

\section{Abstract}

Seismic microzonation of urban areas uses to be determined from few soil response measurements in each area. In consequence, results can be 
considered correct only in the case of possible depth-dependent soils, being cause of imprecision the existence of lateral soil changes. Ground penetrating radar (GPR) could be a useful tool to determine, previously to the passive seismic measurements, the location of geological structures. Moreover, depending on the ground materials, the GPR energy is randomly backscattered. Consequently, the background noise in the radar scans increases. Therefore, the analysis of the amplitude of the noise could be a useful method to determine changes on the ground characteristics. The analysis of the background GPR amplitude noise is tested in two radar lines, crossing the city of Barcelona. The results show significant differences in the background noise amplitude in the Ascans that could be used to define zones in the city depending on the noise level. These changes on the amplitude are associated to the backscattered energy as consequence of soil characteristics. Hence, the analysis of the variation of the background noise amplitude allows defining the possible location of subterranean streams, paleochannels and other structures crossing the plain of the city. Radar results are also compared to ambient vibration measurements, using the spectral $\mathrm{H} / \mathrm{V}$ quotient, and to historical and contemporary information. The application of the methodology underscores the ability of the evaluation of the backscattering associated to the background noise in the scans in the detection of sharp geological changes in sedimentary deposits.

Keywords: Ground-penetrating radar, backscattering, seismic nanozonation, shallow geology, Barcelona, $\mathrm{H} / \mathrm{V}$

\section{Introduction}

It is well known that the soil characteristics can determine changes in the amplitude of the seismic waves. The evaluation of the geographic delineation of areas that have different soil response is named seismic zonation. This process can be considered at different scales, from regional to local. Seismic microzonation defines the different seismic zones in an area, attending to the local shallow geology. This evaluation is becoming more important in cities because local soil characteristics could significantly affect to damage caused by 
earthquakes. The zonation analysis involves geological, seismological and geotechnical ground information. One of the most suitable methodologies applied to determine microzones is the procedure proposed by Nakamura (1989). The method is based in calculating the vertical to horizontal spectral ratio of ambient vibration.

However, in some cases, the numerous and sudden geological changes makes necessary a more rigorous zonation of the area, with detailed description of zones having similar size than the soil elements. This exhaustive zonation is called nanozonation and requires extensive and complete ground information. The nanozone could be defined as the area of each geological structure presenting homogeneous soil response (Salinas et al., 2014). In this case, the main difficulty associated to Nakamura's methodology is the huge number of measurements needed to properly define the soil behaviour in extensive zones where the soil lateral variability is significant. Each one of the measurements is time consuming, and the study is difficult and hard, mainly in the case of big and populated cities. Traffic, building density and numerous civil infrastructures hinder the ground evaluation tasks. The optimization of the process is, therefore, imperative. Consequently, the previous knowledge of those buried targets affecting soil response could become useful information to determine the areas that need high density of seismic measurements and the most homogeneous areas where the measurement points could be more separated. Consequently, other surveys might be tested to be used as preceding soil evaluation. This prior assessment could provide information about the different shallow geological structures, helping in the configuration of the vibration noise measurements grid, saving time efficiently. In this work, the previous soil assessment is carried out by means of ground penetrating radar (GPR). This geophysical survey consists of the detection of ultra-wide band electromagnetic (EM) signals previously emitted by a transmitter antenna. The impulses propagate through the medium, being affected by the EM properties of the materials that depend on their physical properties. Changes in the dielectric permittivity, in the electrical conductivity or in the magnetic permeability produce partial reflection of the energy and determine the characteristics of the wave. The EM properties affects also to the velocity of the waves, their frequency 
content and their amplitude. Hence, the analysis of the received waves could determine possible changes in the soil materials properties. It is known that porosity and water content affects significantly the wave propagation velocity (e.g., Topp et al., 1980, Greaves et al., 1996). A complete description about the method and the effect of the materials properties on the GPR wave behaviour could be found in Daniels (2004).

GPR receives the energy scattered in targets embedded in the medium, as consequence of the contrast in EM properties. As a result, energy is reflected in the targets and it is possible to determine their possible geometries and sizes. Common GPR applications are based in the detection of this reflected energy (e.g., Pérez-Gracia et al., 2012, Arias et al., 2007). In many surveys the energy is also partially scattered in small size targets. This energy is superimposed to the reflected waves, making it difficult the radar data interpretation, because accurate interpretations require low signal to noise ratio (SNR). However, the noise added to the signal as a result of random scattered energy could also provide information about the underground materials characteristics. Several tests demonstrates that the changes on soil materials could be associated to changes in the radar data random scattered energy (Pérez-Gracia et al., 2010; Salinas et al., 2014; Santos-Assunçao et al., 2014). The effect of the granular materials in the evaluation of pavements has been studied, demonstrating an increase of the backscattered energy, detected in the radargrams as an increase of background noise (Al-Qadi et al., 2008; Krysiński and Sudyka, 2013).

The objective of the work described in this paper is the study of two main streets of Barcelona city (Mallorca Street and Diagonal Avenue) using a methodology that allows detecting geological changes based on the amplitude of the backscattered energy, and the subsequent evaluation of that methodology in broad field studies in cities. Radar data was analysed using a common B-scan data processing and also using the amplitude of the backscattered energy. The first analysis provides information about buried objects and ground discontinuities. Those targets are defined analysing the signal amplitude after data processing in order to minimize the effects of the noise, improving the signal to noise ratio (SNR), and reconstructing the shape 
of the targets. The second data analysis was designed to determine the average noise ratio in each A-scan due to backscattering. The evaluation of SNR provides information about zones where the energy is highly scattered, most likely due to characteristics of the geological units.

Both methodologies were applied in the survey of Barcelona city, with the objective of obtaining previous information, useful in detailed nanozonation study. It is remarkable that Barcelona city presents a great lateral variability on geological materials and structures as a consequence of its topography and geographical location (between the sea and a mountain chain). This variability makes necessary nanozonation in order to determine an efficient soil response division. Several formerly tests demonstrate the potential of GPR surveys in nanozanation (Pérez-Gracia et al., 2010; Salinas et al., 2014). In those previous analysis, radar data obtained with $100 \mathrm{MHz}$ and $25 \mathrm{MHz}$ centre frequency antennas were compared to borehole information and to passive seismic results using the horizontal to vertical $(\mathrm{H} / \mathrm{V})$ spectral quotient.

\section{The city: emplacement, history and geology}

Barcelona is a city in NE Spain. It is surrounded by a mountain range of low height (512 $\mathrm{m}$ above sea level) and limited at East by the Mediterranean Sea (Figure 1). A large part of the city is placed on a plane, a semigraben basin of about $12 \mathrm{~km}$ long and $5 \mathrm{~km}$ wide, bounded by two coastal horst structures: the Collserola hills at the Northwest and the Montjuic mountain at the South. Two rivers and their deltas make the city limits at South (Llobregat river) and at Northeast (Besos river). Therefore, the city is built over Quaternary deposits overlaying Tertiary materials and the Palaeozoic substrate that outcrops in the surrounding mountains (Error! Reference source not found.). The plain deposits are old consolidated quaternary soils called tricycle, composed by red clay, eolian mud and rounded gravel. This geological sequence of three materials is replicated several times, being that characteristic the reason of the deposits name (tricycle). Thicknesses of quaternary deposits are highly variable (see cross sections in Figure 2).

A vast number of small water currents flowed from the mountains to the sea. However, the enlargement of the city and the construction of the several 
neighborhoods during the $\mathrm{XIX}$ and $\mathrm{XX}$ centuries caused the hiding of these water currents under anthropogenic filling and civil constructions. The coastline was also significantly modify as consequence of ground materials deposited by the streams and the human action (Acebillo and Folch, 2000), dating the first documented coastline change from the Roman epoch.

Most likely, the most important change in this city started in 1855, when the architect Ildefonso Cerdà proposed the structure of the Eixample district. Figure 1 shows an historical map where de dimensions of the proposed enlargement are highlighted. The old city walls were demolished and the new neighborhood construction was developed following a geometric structure. The city was importantly enlarged and extended on the plain, an area occupied until that moment by farm fields and small towns. As a result, many of the shallowest geological settings were covered by the civil structures and anthropogenic fillings. Seasonal streams were stuffed and covered by buildings, roads, bridges and other urban structures.

\section{FIGURE 1}

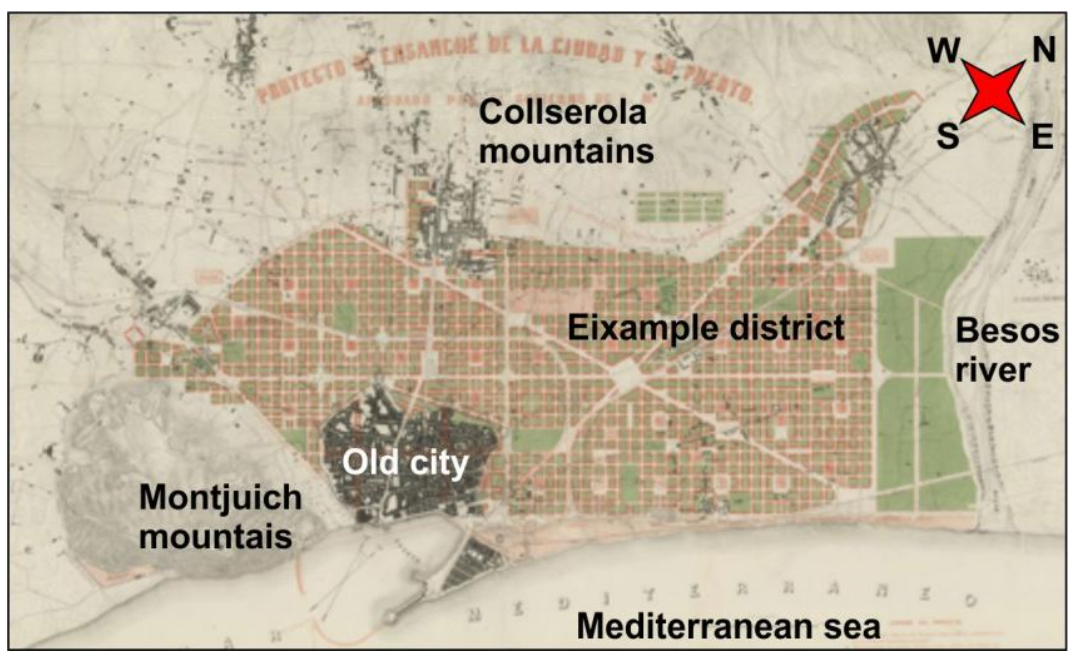

Figure 1. Historical map showing the Project of the Eixample district (Vazquez 1861). The city is surrounded by the mountains, the Besos river and the Mediterranean sea.

Today, even not visible and depending on the rainfall, water content in the sporadic streams fluctuates, and the water courses could be categorized as active or inactive. Independently on the water content, materials in these 
courses and in older paleochannels can be epitomized by their grain size distribution material, disposed in clusters, revealing differences with the media corresponding to other geological units. Boreholes in different points of the city confirm this fact, showing changes as a consequence of the entrainment of sediments in the stream courses.

Historical maps describe these seasonal streams (Aibar and Bijker, 1997; Vazquez, 1861; Arandes, 1998; Anonymous, 1935). Contrasting those documents, it is visible the differences on the streams location, perhaps as consequence of courses alterations. The cause of the observed changes could be natural variations of the water courses or the waterproof of the soil due to civil constructions. Actual maps are defined from historical ones and the interpolation of borehole data (Ventayol et al., 2000; IGC, 2009; ICG, 2011). The discrepancies between the documents, lead to a significant imprecision in the position of those geological structures. 


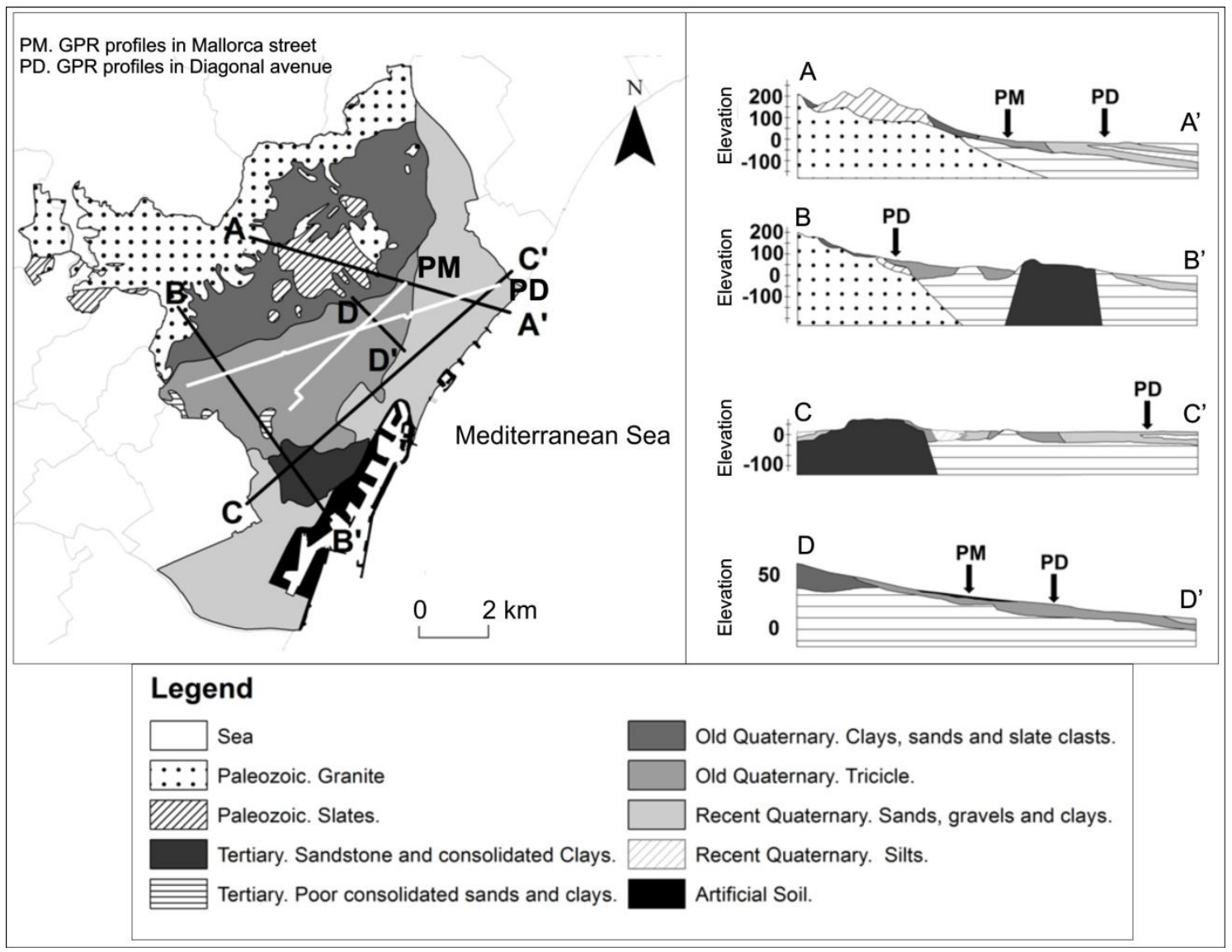

Figure 2. Geological map of Barcelona. Black lines on the map mark the position of the the cross sections $A A^{\prime}, B B^{\prime}, C C^{\prime}$ and $D D^{\prime}$ showed in the right images. White lines on the map indicate the position of the two GPR profiles described in this paper.

\section{Radar data acquisition and processing}

A broad knowledge of the shallow geology of the city is critical in mapping the seismic soil response accurately. Accordingly, the existence of subterranean streams and paleochannels must be considered in the evaluation of soil response, because lateral heterogeneities could be associated to different seismic response (Salinas et al., 2012). Therefore, two radar lines crossing the city were used to detect these particular geological structures. Both radar lines were coincident with two main streets of Barcelona: Diagonal Avenue (DA) and Mallorca Street (MS), being the total surveyed lengths $9.66 \mathrm{~km}$ in DA and 5.28 $\mathrm{km}$ in MS, dividing the distance in sections of about $200 \mathrm{~m}$ in order to facilitate 
the radar data acquisition tasks and the following radar data processing. Figure 3 shows the map of the city with the position of both profiles that traverse the city.

Two different antennas with $100 \mathrm{MHz}$ and $25 \mathrm{MHz}$ center frequencies, were employed in the survey. The position of the antenna during the radar data acquisition was defined with a survey wheel and with a GPS. The direction of the profiles allowed to detect the intersection of the subterranean streams with the profile. The results were compared to different geological and hydrological maps of Barcelona.

\section{FIGURE 3}

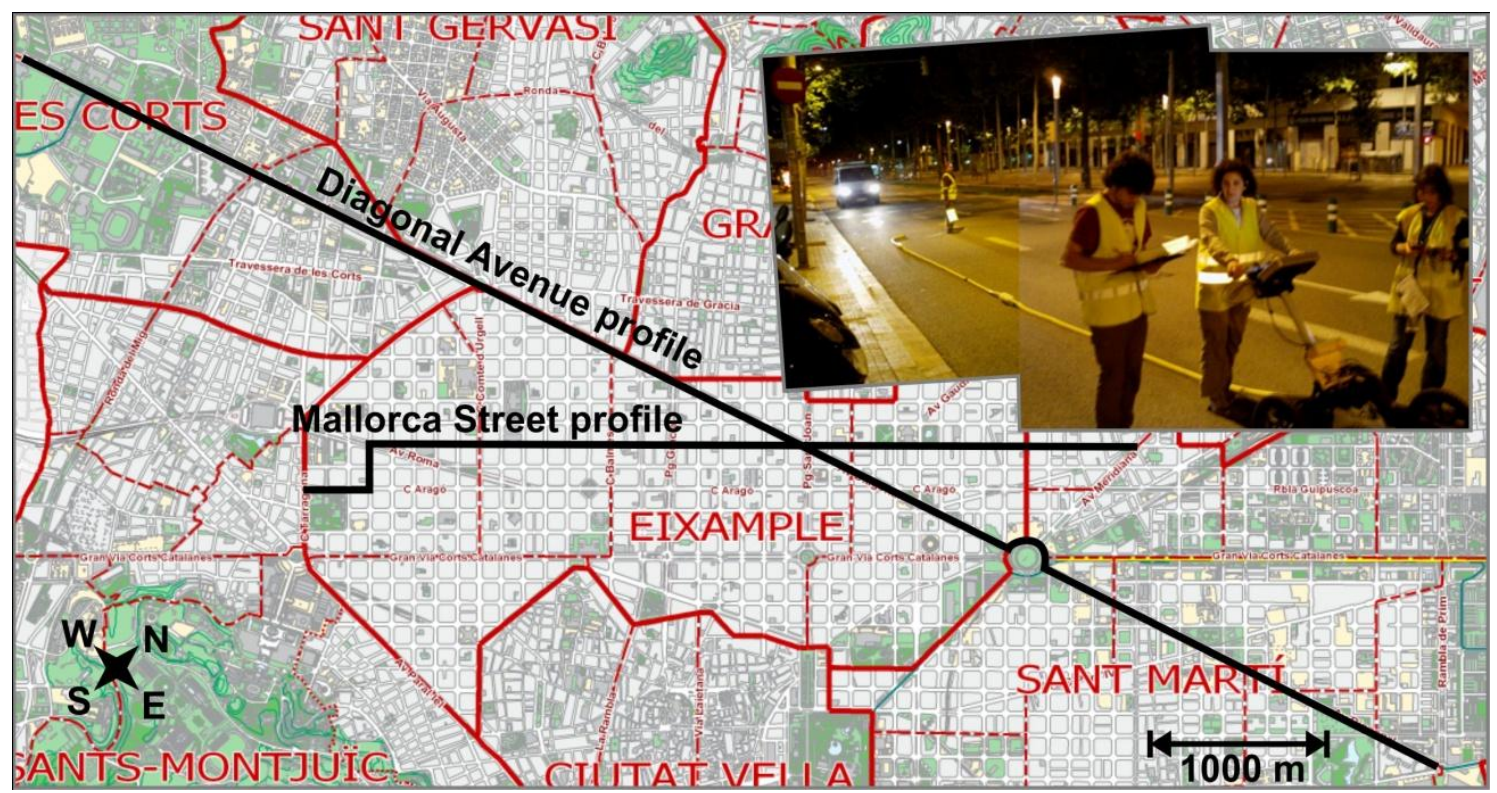

Figure 3 - Radar data acquisition tasks and the position of the two profiles (black lines) on the city map.

Radar data was processed in two different ways. The objective of the first procedure was the detection of discontinuities and changes affecting the shallow geology and civil engineering structures. Therefore, a usual regular processing sequence was applied in order to diminish noise and improve the signal reflected on the contact between different ground materials and buried targets. The second one was designed in order to emphasize the effect of the random backscattering on the A-scans. The energy scattered in irregular materials of the soil introduce small and irregular signal (background noise) in 
the radar data, usually considered as noise. This "background noise" is a response for some structure of stochastic character. It is repeatable in repeated measurements (if the course and position is controlled perfectly). But the detailed structural interpretation is not possible in practice, because of large ambiguity related to complexity of this granular-like structure having space characteristics comparable to the local wavelength.

The background noise as consequence of this phenomenon is different from other background noise that in many cases appears in the A-scans due to the electromagnetic noise inherent to the antenna and GPR equipment. This electromagnetic noise is not repeatable in repeated measurements and it is observed also for time preceding the direct wave (where any structural signals are absent).

\subsection{Regular data processing to detect discontinuities}

The sequence processing was applied in order to highlight the effect on the Bscans as consequence of reflections on targets, improving the signal to noise ratio. The different steps in the sequence were: subtract mean (dewow) with a 200 ns time window, background removal, manual gain function (no gain applied between 0 and $80 \mathrm{~ns}$, linear gain with a slope of 0.04 , and constant gain 12 since $400 \mathrm{~ns}$ ) and band pass filter, being the cutoff frequencies $12.5 \mathrm{MHz}$ and $37.5 \mathrm{MHz}$. Dewow allows eliminating low frequencies in each A-scan, correcting possible baseline deviations. Background removal facilitates to diminish horizontally coherent energy that appears as consequence of direct wave and reflections on the surface and on buildings along the profile. Finally, band pass filter eliminates those frequencies out of the desired range that could be caused by widespread electromagnetic noise in cities.

\subsection{Radar data processing to highlight the random scattering}

This second processing method consists of analyzing the oscillation of the existing scattering amplitude in all traces that affects the signal like background noise (Santos-Assunçao, 2014). The process consists of defining an average 
value of the scattered amplitude for each A-scan. The collection of values are compared along the $x$-direction (horizontal distance along the survey line). Figure 4 presents the four steps sequence processing, scrutinizing changes on the amplitude.

The first step consists of applying a subtracting average function. This function is calculated using the coherent signal that appears in the B-scan as consequence of the signal reflection on targets, obtaining an average value that is subtracted from all A-scans. As a result, coherent signals are reduced and incoherent amplitudes remains on the processed radar data. Several previous test profiles carried out in well documented zones of the city, exhibited changes on the backscattered amplitudes depending on the ground materials, being higher over known subterranean streams (Perez-Gracia et al. 2010; Salinas et al., 2014).

The second step involves the application of a DC detrend (between time 0 ns and $30 \mathrm{~ns}$ ) to remove possible low frequency content that could be added to the signal during data acquisition or processing.

The third step implicates the selection of a proper time window (between $300 \mathrm{~ns}$ and $600 \mathrm{~ns}$ ). The maximum amplitude and the average amplitude are calculated in this time window. The fourth and last step consists of the representation of both values in front of the A-scan position.

FIGURE 4 


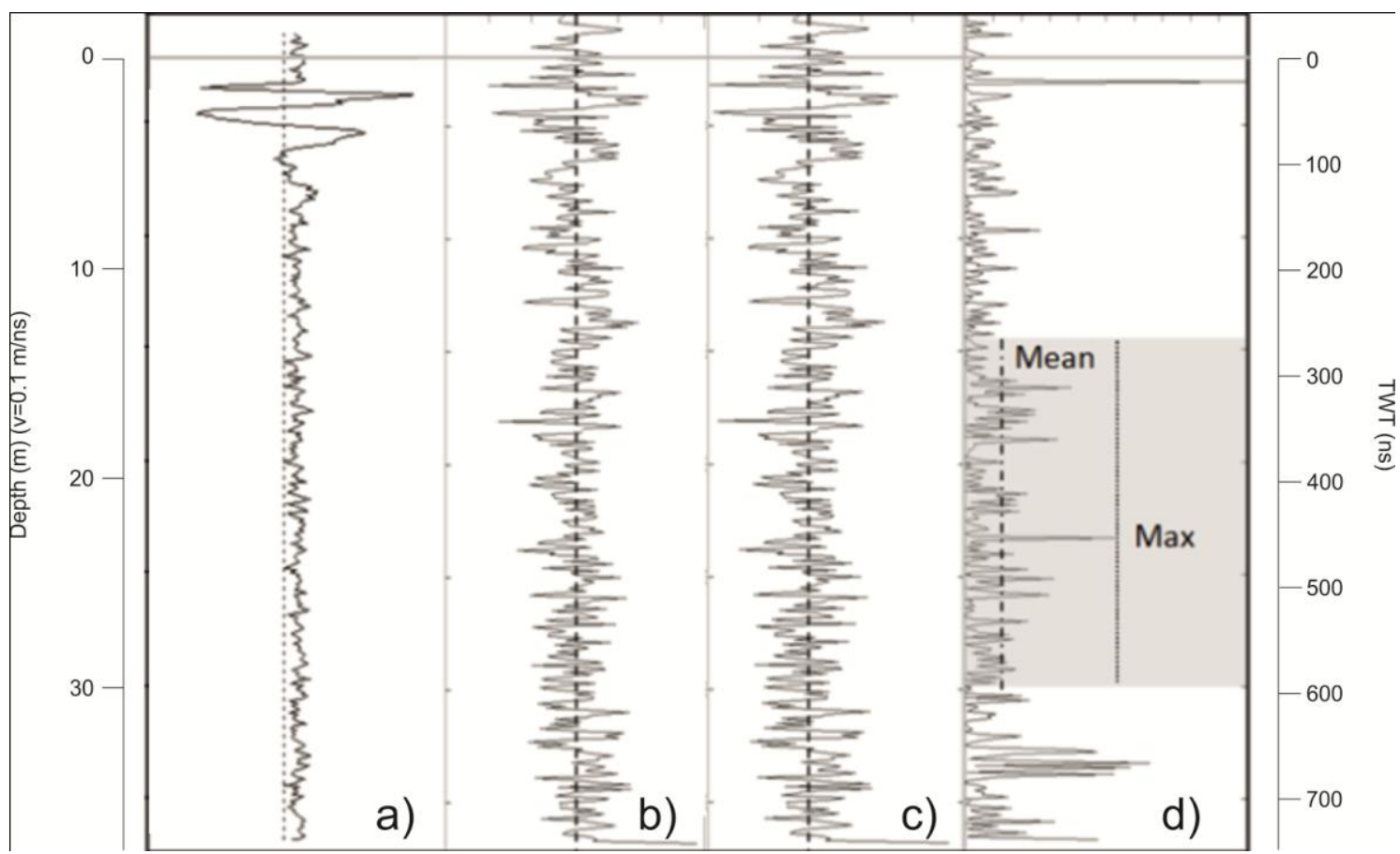

Figure 4- Radar data processing to emphasize the incoherent signal. a) Raw data. b) A-scan after subtracting the average signal. c) The result of apply a DC detrend. d) Absolute value of the amplitudes and selection of the time window. On this temporal window, the average and maximum noise are indicated.

\subsection{Noteworthy aspects in dense cities surveys}

Geophysical surveys in crowded cities are always affected by several particular problems that must be carefully considered. Operating GPR antennas of 100 $\mathrm{MHz}$ and $25 \mathrm{MHz}$, especially in long radar lines obligates to cross high traffic zones or restricted areas. However, the most important difficult is associated to the urban noise. Two main noise sources could affect radar images in city surveys. One of them is clutter caused by numerous external targets. Buildings, tunnels and other civil engineering structures are possible clutter in radar data. Therefore, it is basic to select properly the site for radar lines, as well as to consider exactly the different structures that could disturb the signal. Other sources of noise are electromagnetic emissions. Engines and telephonic or radio emitters produce electromagnetic fields that could be superimposed on the radargrams.

Figure 5 shows two examples of usual clutter and electromagnetic noise affecting surveys in cities. Radar data in Figure $5 \mathrm{a}$ is obscured as consequence 
of clutter produced in an overpass. Radar data showed in Figure $5 \mathrm{~b}$ contain noise due to a local radio emission. The emitted radio wave is superimposed to the GPR signals reflected on ground targets. The significant amplitude of this emission obscures the anomalies from the ground. The noise is more important when the frequencies of the radio emission are close to the center frequency of the GPR antenna. In this case, the antenna bandwidth was about $50 \mathrm{MHz}$, being the center frequency approximately about $25 \mathrm{MHz}$, and the external radio emission was in this range of frequencies.

Superimposed signals, in both cases, hides the signal produced by reflections in targets in the ground being difficult or even impossible the radar data interpretation. In some cases, careful data processing allows minimizing some noises, mainly when the frequency content of the noise is far from the center frequency of the signal. In the study, several test were carried out in order to identify the best processing methodology for each case (Santos-Assunção and Perez-Gracia, 2011). Reducing the noise was possible in the case of low SNR. Hence, during the radar data processing the few parts of the B-scans with high external noise level were discarded.

FIGURE 5

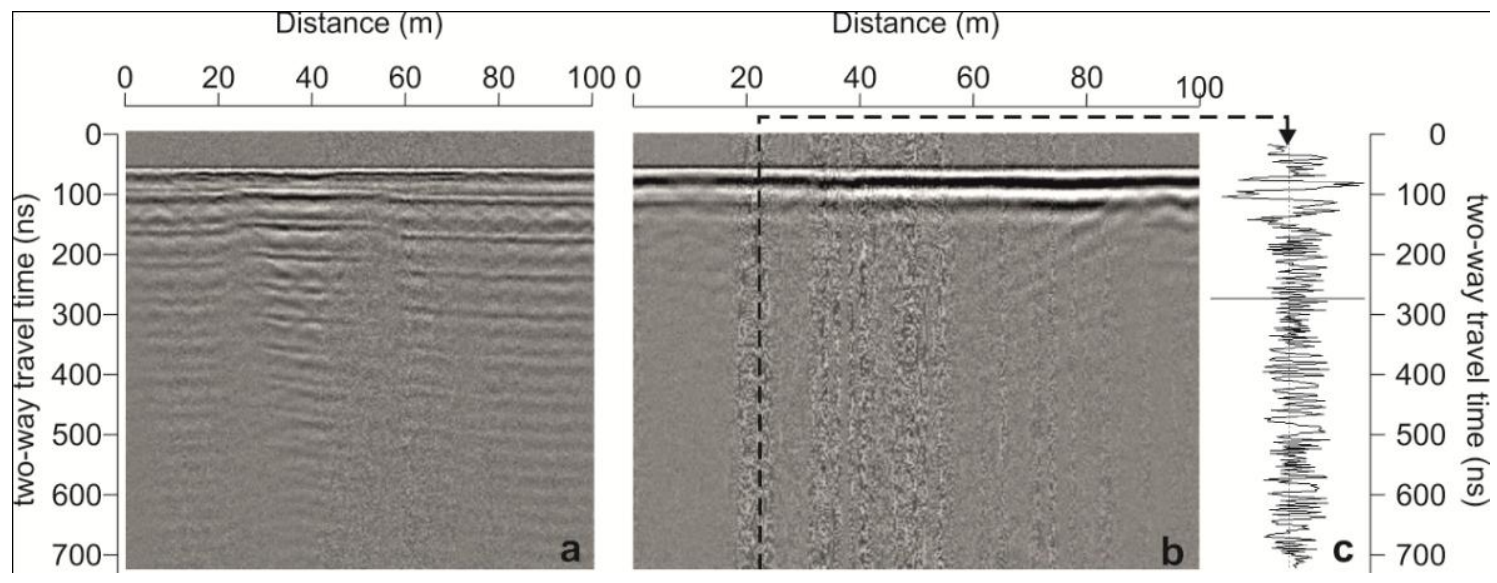

Figure 5 - Noise superimposed to GPR signals. a) Clutter caused by multiple reflections in an urban structure in Diagonal Avenue. b) Noise produced by a radio wave emission in Mallorca Street. c) A-scan from the radargram affected by radio emissions.

\section{Relevant results}


Radar data allow obtaining results especially relevant in some zones where the relationship between backscattering and geological targets was clearly determined, showing an important concordance with passive seismic results and historical data. In these zones the radar images obtained with the two different data processing methodologies show also an important correlation between anomalies as consequence of reflection on interfaces and the increase of the scattered energy.

The study was particularly focused in some significant zones that were defined based on these relevant results and on the existence of special buildings or sudden changes in the ground geology close the radar lines. Two examples of significant zones are described and discussed in this paper.

The first zone corresponds to the junction of Mallorca Street with Diagonal Avenue (Figure 6a). The area corresponds to the intersection of the two radar lines, allowing the comparison of results. Moreover, attending to the historical maps, two seasonal streams converge in this zone into a single one. Other important characteristic of this zone are several relevant Art Nouveau buildings. Geological data are available from several close boreholes.

The second zone is a $400 \mathrm{~m}$ long profile in Mallorca Street (Figure 6b). Historic documentation indicates that two subterranean and seasonal streams most likely cross this profile. However, radar results point to different locations of the anomalies that not correspond exactly with the position of the streams defined in the maps.

FIGURE 6 


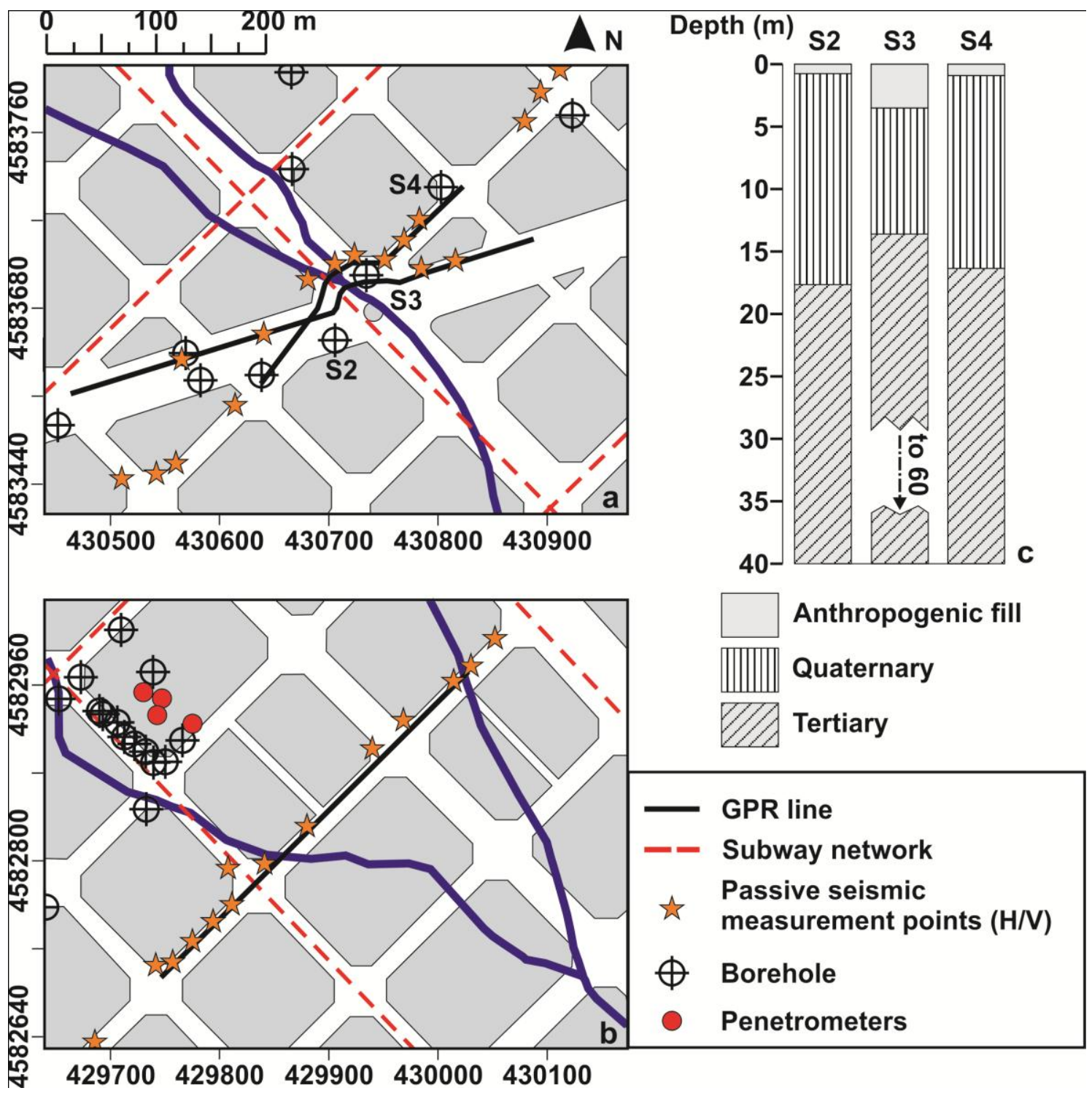

Figure 6. Three of the GPR lines carried out in Barcelona. a) Two radar lines crossed at the intersection between the Mallorca Street and Diagonal Avenue. b) $200 \mathrm{~m}$ profile in Mallorca street c) Shallow geology in boreholes S2, S3 and S4.

\subsection{Zone 1: Mallorca street intersection with Diagonal Avenue}

In this zone, radar line along Mallorca Street intersects the radar line in Diagonal Avenue (Figure 6). Both are placed on the Old Quaternary plain (Figure 2). Hydrogeological maps shows the possible location of underground streams in the area, deduced mainly from historical data. These maps indicate that most likely radar lines intersect an important subterranean watercourse just 
in the junction of two streams. Shallow geology is obtained from boreholes close the GPR line (Figure 6).

This geology is characterized by granular-like structure formed by alternating clusters of different materials (pebbles, matrix) characteristic for alluvial sediments, especially in vicinity of mountains.

The large pebbles potentially can generate this kind of stochastic signal (i.e. the background noise). But the $25 \mathrm{MHz}$ center frequency antenna would be particularly efficient in generation scattered signal in the case of objects having diameter of order several decimeters up to about one meter. Thus it is not ever granulation in standard meaning. This is the case of the geological structures existing in the surveyed area, being expected an intense scattering of the energy.

\section{a) Radar line in Mallorca Street}

This profile is a $268 \mathrm{~m}$ length radar line (Figure 7).

After the first data processing it is evident that several of the anomalies in the radar image are consequence of reflections on man-made structures. Other anomalies could be associated to shallow geology. The complex and irregular Quaternary deposits cause non-continuous images of the targets. Clutter at lower travel times, caused by external targets in the surface is also remarkable. The upper part of the radargram can be divided in two principal anomalous zones: reflections on the underground structures (position between $160 \mathrm{~m}$ and $200 \mathrm{~m}$ ) and reflections on basements of buildings (position between $50 \mathrm{~m}$ and $100 \mathrm{~m}$ ). At higher two-way travel times, the possible location of the streams are delineated by anomalies at both sides.

The second radar data processing reveals the behavior of the average background noise amplitude that could be associated to random backscattering (Salinas et al. 2014), normalized to the maximum value. This noise is highly increased in the area where the possible subterranean stream was previously identify. Accordingly, the representation of backscattered normalized amplitude along the radar lines provides information about the distribution of cluster of materials with different grain size. 
The normalized scattering amplitude $A_{n}$ is defined as a linear rescaling of the previously defined maximum amplitude $A$. The rescaling formula attributes value 1 to $A_{n}$ when $A$ reaches its maximal value $A_{\max }$ (observed in all considered radar profiles), and $A_{n}$ gets value 0 when $A$ has the value $A_{\min }$ of the lower observed background noise level:

$A_{n}=\frac{A-A_{\min }}{A_{\max }-A_{\min }}(1)$

FIGURE 7

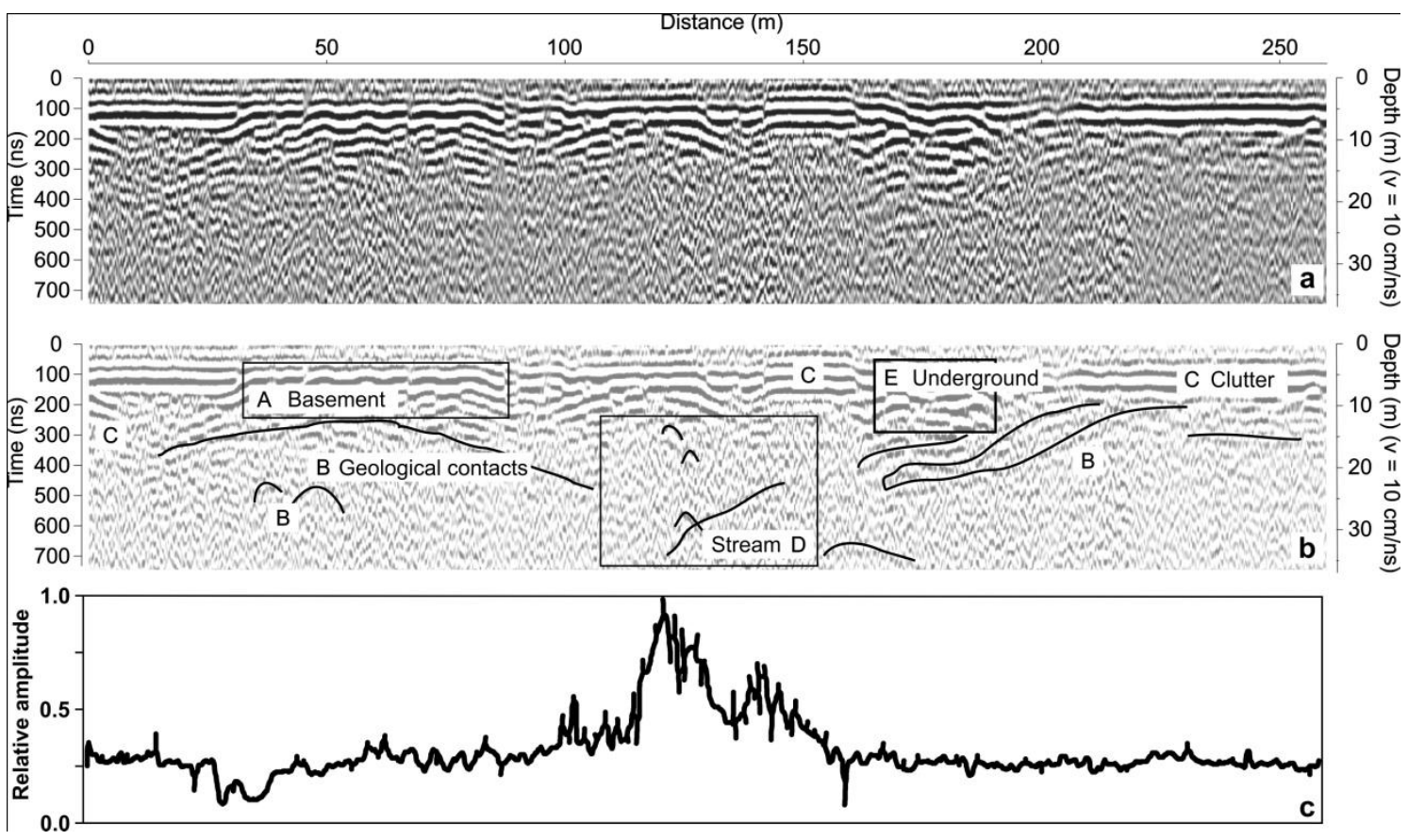

Figure 7. Radar line obtained in Mallorca Street. a) Processed GPR data. b) Possible interpretation, being the main anomalies: A (Close buildings elements), $B$ (geological structures), $C$ (clutter in external targets), $D$ (possible underground stream) and $E$ (underground train station). c) Average amplitude of the randomly scattered energy in each A-scan. Higher amplitudes correspond to the stream location.

b) Radar line in Diagonal Avenue

The $430 \mathrm{~m}$ length profile along the Diagonal Avenue (Figure 8) intersects the radar line in Mallorca Street, just before crossing the possible subterranean stream identified in the maps. High A-scan background amplitude associated to 
backscattered energy appears in a zone between $120 \mathrm{~m}$ and $150 \mathrm{~m}$, indicating the presence of the possible subterranean stream, in good correspondence with results from the crossed profile in Mallorca Street and with the historical documentation. The zone affected by high backscattered energy is wider than the zone marked in the maps as a stream. Two possible causes could explain this small discrepancy between the experimental data and existing maps:

a) The proximity of the two streams near the junction of the two GPR profiles. It could be possible not to differentiate between both targets, being the zone affected by backscattering energy wider that in the case of a single stream.

b) Possible changes in the course of the stream, being wider the zone affected by the water course.

Other deeper anomalies in this profile, visible at different depths, could correspond to geological structures. Other shallow anomalies are associated to the underground station, to man-made structures and to clutter in external targets.

FIGURE 8

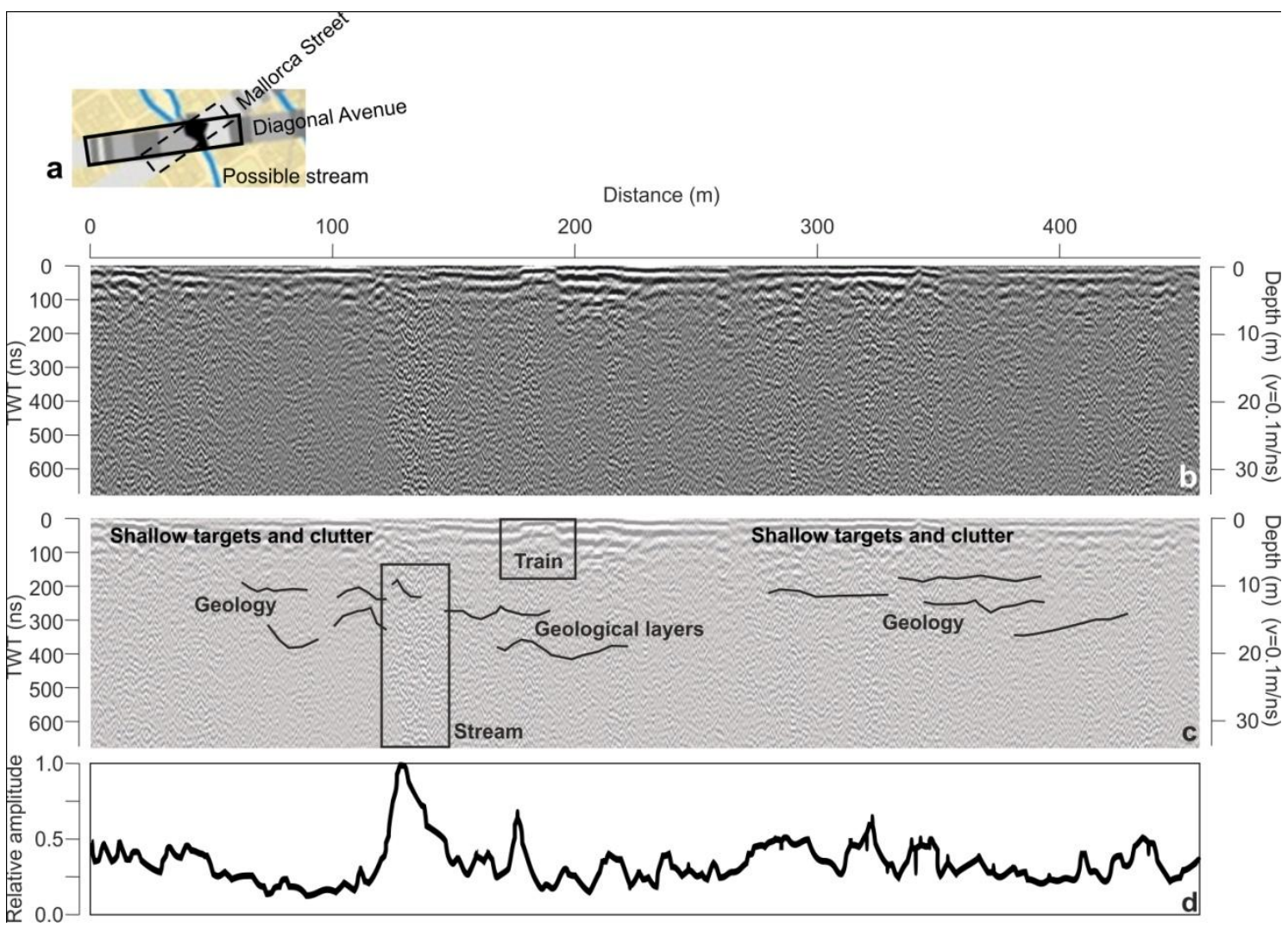


Figure 8 - Radar data obtained in the Diagonal Avenue. a) Location of the radar line with respect the radar line in Mallorca Street and the position of the subterranean stream defined by historical maps. b) GPR processed data. c) Possible radar data interpretation, indicating the emplacement of the stream.d) Behavior of the background noise amplitudes in the A-scans, most likely as consequence of the backscattering. The higher amplitude corresponds to the subterranean stream location.

\subsection{Zone 2: Mallorca Street in the city center}

Zone 2 corresponds to a $400 \mathrm{~m}$ length portion of the complete survey along Mallorca Street. The application of the two sequences of data processing indicates the possible existence of one subterranean stream placed between $270 \mathrm{~m}$ and $290 \mathrm{~m}$ (Figure 9). This zone is characterized by anomalies that could be associated to these geological structures and also by an important rate of randomly scattered energy. However, radar images denotes the presence of other irregular anomalies that could be associated to the shallow sedimentary geology, most likely to gravels deposits. Close the possible location of the stream, noteworthy reflections occurs on the structures of the tracks and train tunnels.

The analysis of the changes in the random backscattered amplitude along this section is shown in Figure 10. Two graphics display the maximum and the average amplitude in the selected time window. In both cases, the increase in the amplitude denotes the presence of the subterranean stream.

FIGURE 9 


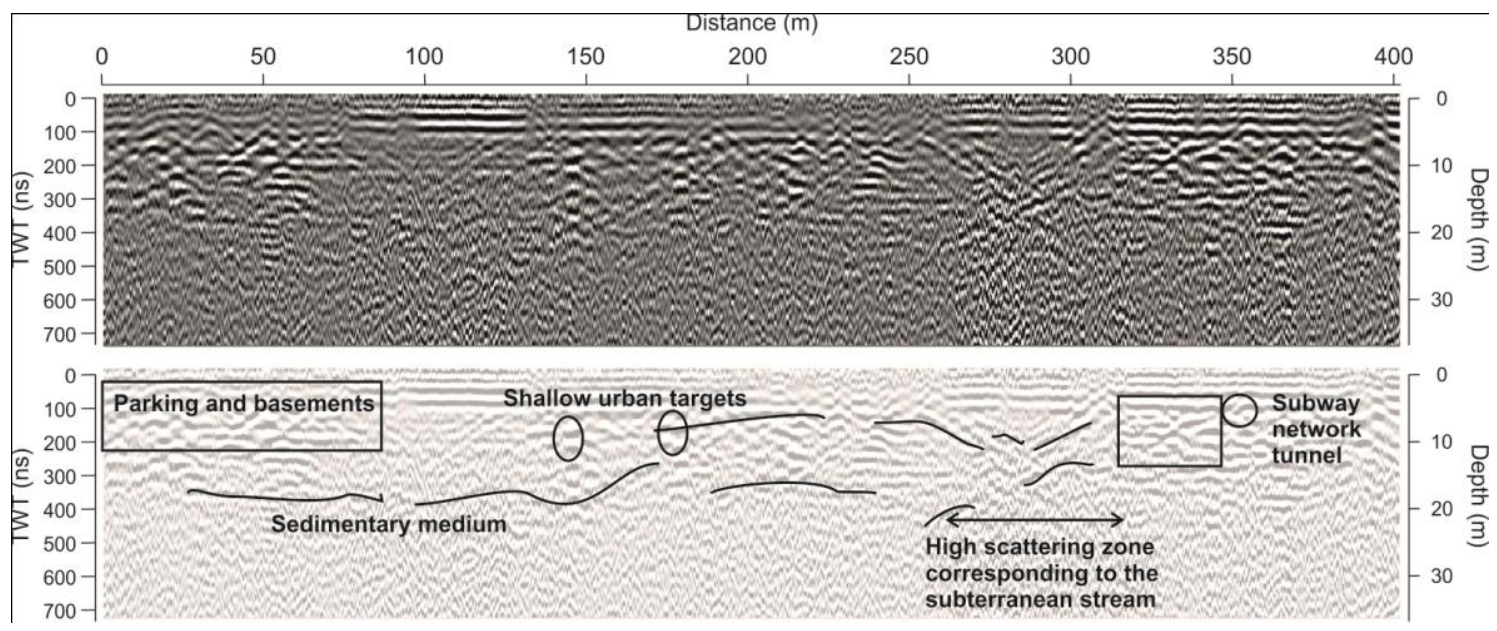

Figure 9. Fragment of Radar data acquired in Mallorca Street and possible interpretation. The increase in the amplitude of the random background noise in the $B$-scan could indicate the position of the subterranean stream

FIGURE 10

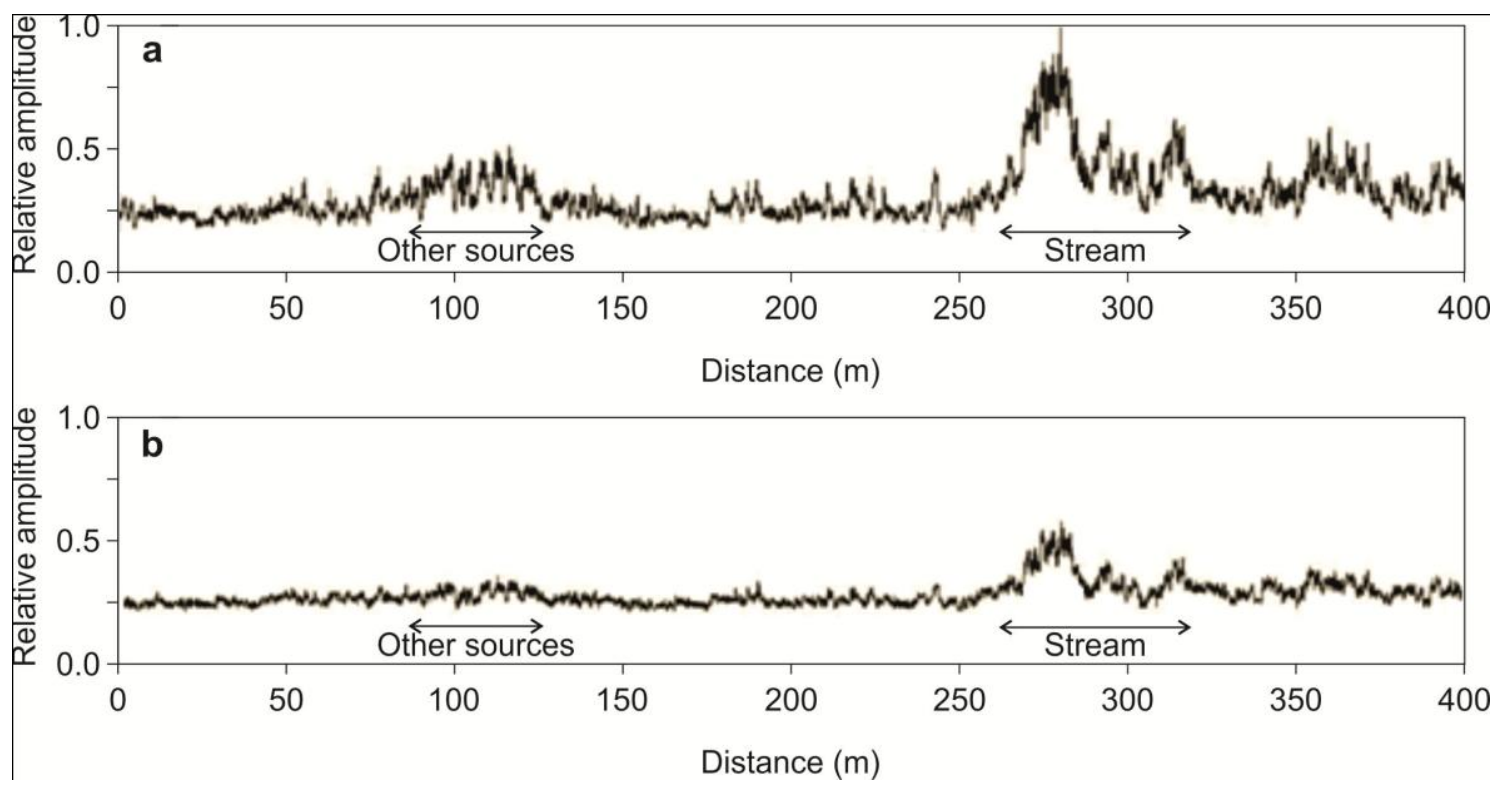

Figure 10. The higher amplitude in the background noise of the A-scans denotes the possible existence of the stream. a) Analysis using the maximum amplitude in the time window. b) Analysis using the mean amplitude in the interval.

B-scans suggest the zone with higher backscattering noise, but the analysis of its amplitude (Figure 10) underscore better the zone. The analysis using the maximum amplitude in the time window describes with higher accuracy the 
zones with backscattering sources. However, the analysis of the average amplitude in the time window allows minimizing the softer scattering effects.

The results were compared to historical maps. It is remarkable that the position defined using GPR results not corresponds exactly with the position marked in those maps, although all the possible locations are close one to the other, being the maximum separation about $40 \mathrm{~m}$. It is interesting to remark also that the GPR data describe a wide zone affected by the backscattering noise, and not only a narrow section in the radar line. Figure 11 evidences the results compared to the existent documentation.

The discrepancy detected between GPR and historical data could be consequence of the change of the subterranean watercourse, most likely due to human constructions. Actual basements and retaining walls can cause alterations of the watercourse. In addition, maps were elaborated with historical information that uses older projections and interpolating punctual borehole results. The more extensive zones in GPR images associated to streams could be caused also by possible historical changes on the watercourse. These variations produce enlargement of the area with characteristic scattering materials. As consequence, the area where the energy is randomly scattered is wider than the actual course of the stream.

\section{FIGURE 11}

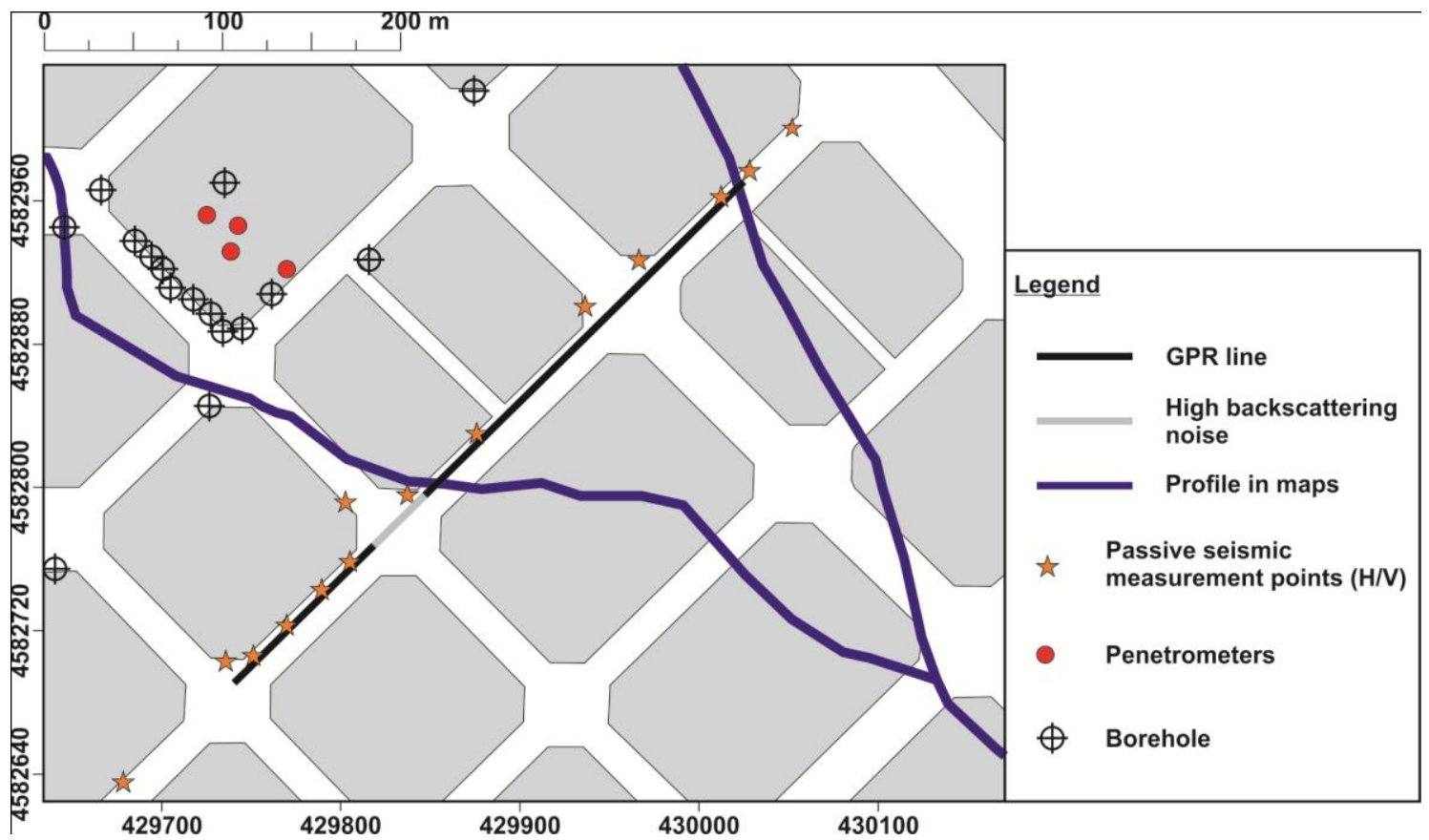


Figure 11. GPR line and the zone where the energy is highly backscattered, compared with the location of the underground stream proposed by Ventayol et al. (2000).

The anomalous zone detected with GPR is characterized by a central zone of about $15 \mathrm{~m}$ length with maximum backscattered energy. The amplitude of the background noise in the A-scans decreases at both sides. These characteristics are visible in both graphs of the Figure 10, although the possible position of the underground stream is better highlighted using the maximum amplitude than the average amplitude. However, the maximum amplitude is greatly affected by other sources, being minimized in the case of processing with the average amplitude.

The wide zone affected by the backscattering of the energy in B-Scans seem to indicate that it is not possible to define exactly the position of subterranean stream but a flow zone, delimitating sections with fluvial deposits.

\section{General results}

The two particular cases described in the paper are examples of the results obtained in the complete study. Concordance and discrepancy between documental information and radar data were analyzed carefully along the whole profile. Anomalies as consequence of targets and scattering of the energy were used to determine the zones with possible existence of materials that could indicate the existence of water flows, fluvial sediments and paleochannels.

The background noise in the defined time window of all A-scans was normalized in order to determine changes on the scattering caused in the different zones. The maximum amplitude observed in all radar profiles was equalized to the unit, being zero the lower background noise level. This procedure allowed to determinate quantitatively the responses and to compare them. Results of amplitudes in the two radar lines are presented in Figure 12 (Diagonal Avenue profile) and in Figure 13 (Mallorca Street Profile). The analysis of all the radar profiles indicates that the area affected by fluvial deposits around the streams is narrower close the surrounding mountains of Barcelona, being wider in the lower part of the bed of the stream. 
Results presented in Figures 12 and 13 show that the differences on background noise and peak amplitudes are most important when radar lines cross different geological structures. Moreover, in the Diagonal Avenue profile there is a perceptible crescent trend in the background scattering noise amplitude from the mountain to the sea, being changes noticeable when the line crosses the different geologies that can be divided in three zones, defined based upon surface geology and Prequaternary substratum (Figure 12).

The first zone, (A in Figure 12) corresponds to a deltaic structure: surface geology (recent Quaternary) over a Prequaternary substratum formed by sandstone. The second zone (B in Figure 12) corresponds to the "tricicle" structure overlaying the Prequaternary substratum of sandstone. The third zone ( $C$ in Figure 12) corresponds to the same surface geology than zone $B$, but overlaying a Paleozoic formation where sandstone appears intermittently.

Radar line in Diagonal Avenue crosses the three zones, and radar line in Mallorca Street is only over the zone B (Figure 13). The analysis of the backscattering amplitude shows that maximum amplitudes are highly dependent on the geological characteristics of the soil. Therefore, in the amplitude normalization process, the signal could be nearly insignificant due to the lowest values of the maximum amplitudes, being this effect relevant in the zone B. As consequence, three different zones were considered separately, and the amplitude was normalized with respect to the corresponding maximum amplitude in each zone. Figure 12 presents the results obtained crossing three different zones and, therefore, three different normalizations are used in the same image.

FIGURE 12 


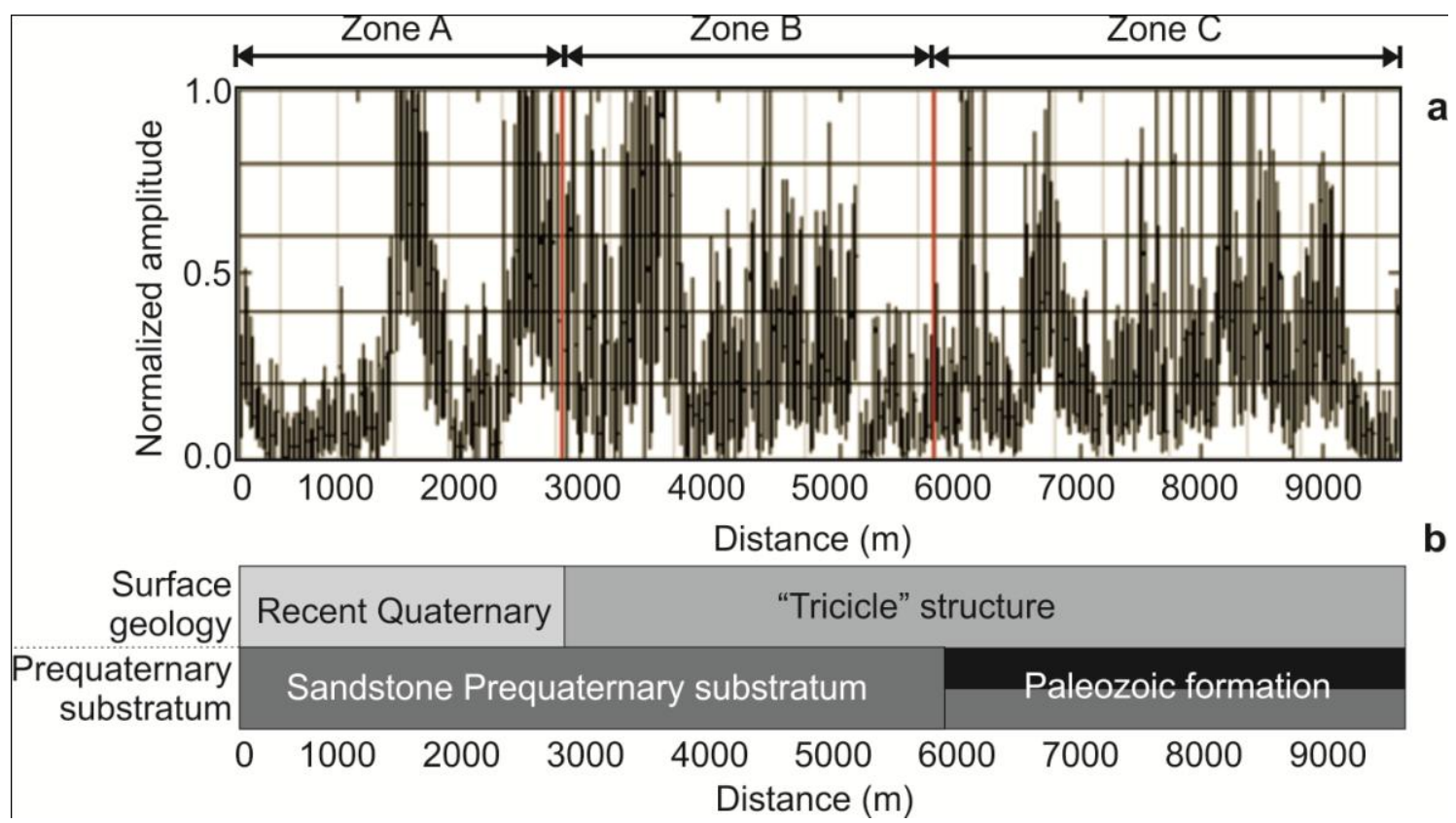

Figure 12. a) Random backscattering amplitudes along the radar line in Diagonal Avenue. The line was divided in three zones depending on the geological units. b) Geological units crossed by the radar line.

FIGURE 13

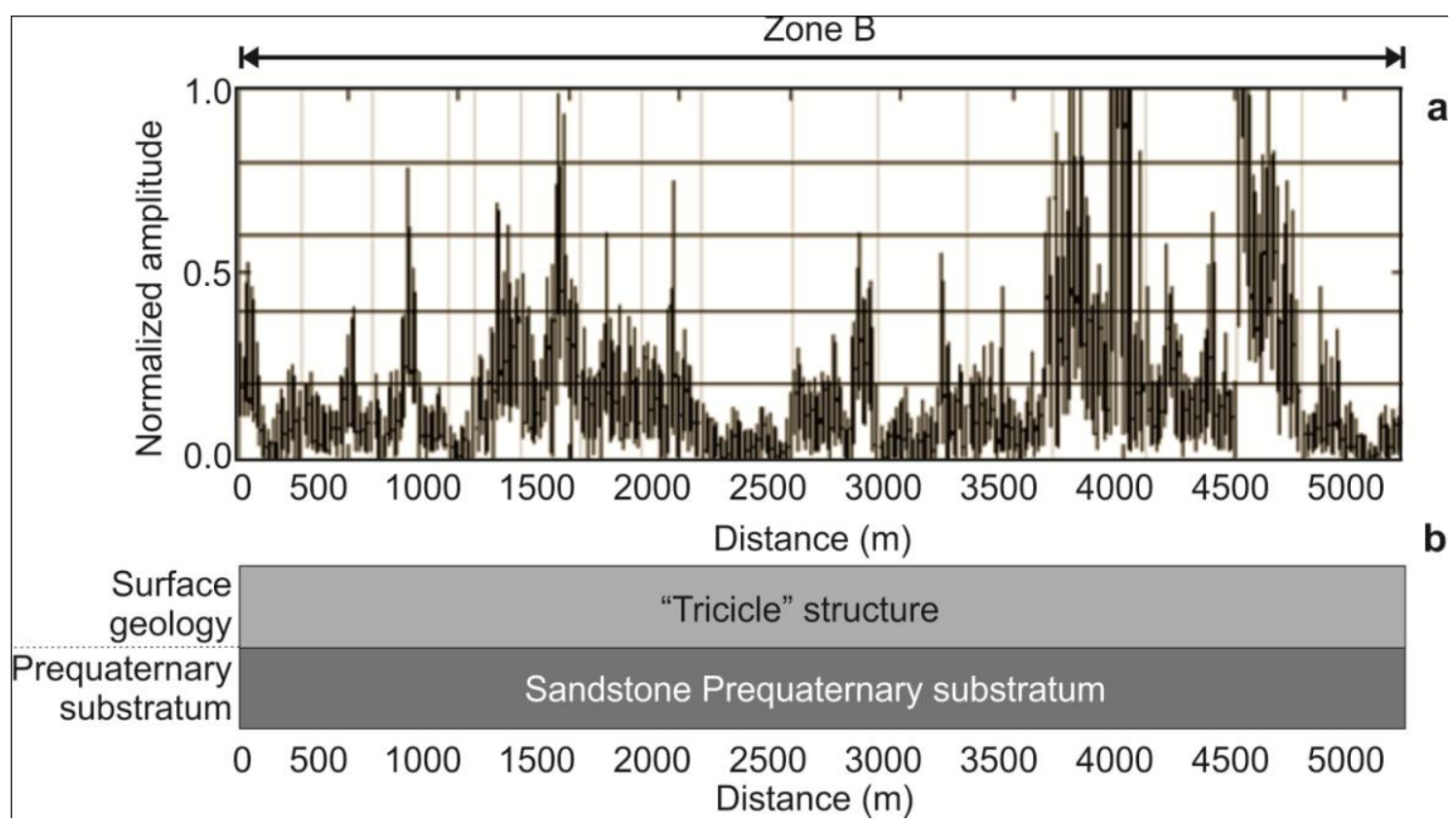

Figure 13. a) Backscattering amplitudes in the radar line along Mallorca Street. The line crosses one heterogeneous single geological unit. b) Geological section along the radar line. 
Using the results showed in Figures 12 and 13, five amplitude levels have been defined and drawing along the line, using darker colors in the case of high amplitudes and lighter colors in the case of lower amplitudes. Figure 14 shows the final result along the Diagonal Avenue, and Figure 15 along Mallorca Street. On the graphs, the locations of streams proposed by Ventayol et al. (2000) are marked with arrows. In many cases, the GPR results are coincident with these positions but, in some cases, discrepancies could be caused by changes on the water courses due to anthropogenic or natural causes. Moreover, the use of historical documentation could introduce additional discrepancies due to the historical base, maps projection and resolution. 
FIGURE 14

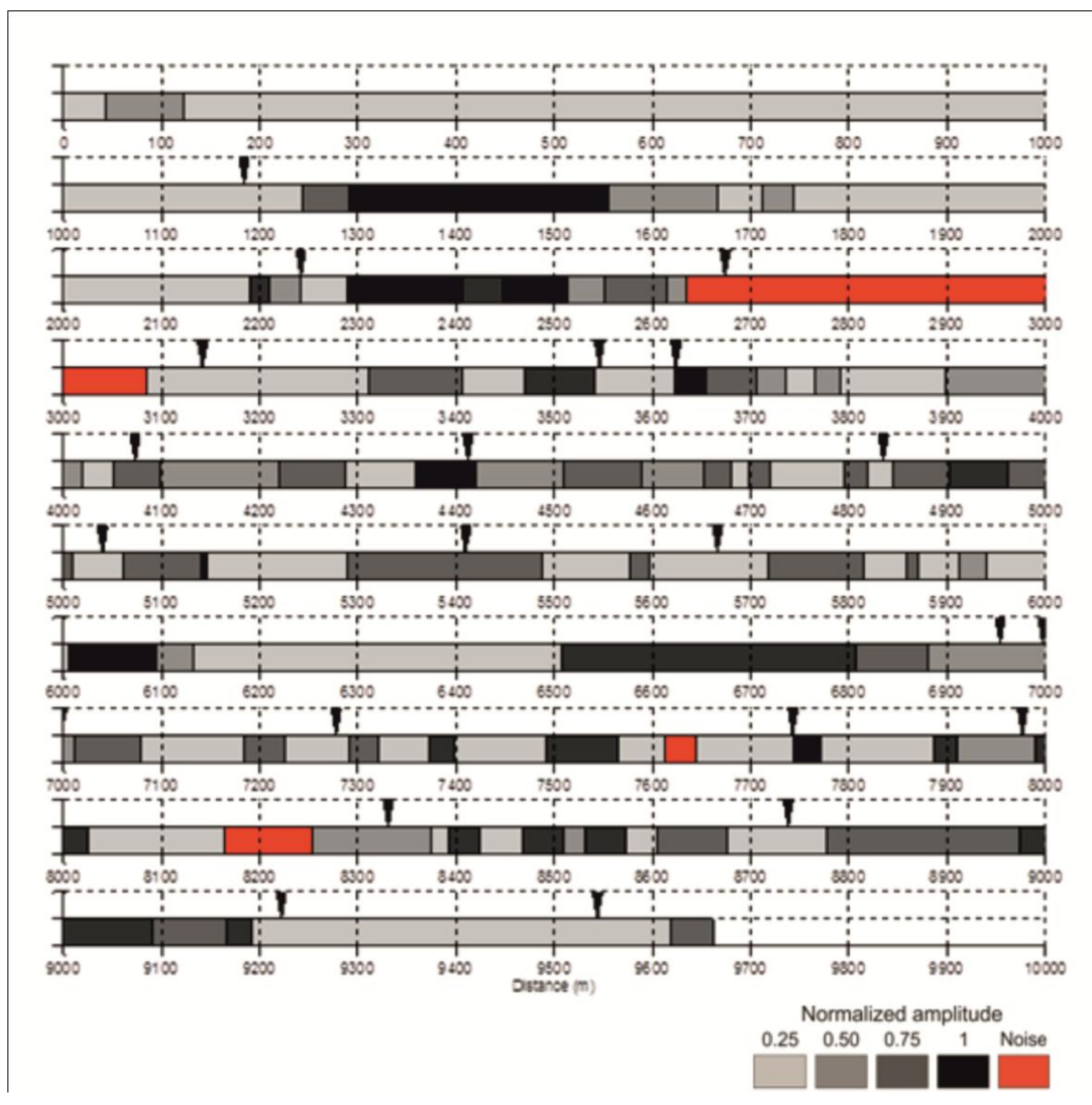

Figure 14. Results in Diagonal Avenue. Higher backscattering amplitude is represented in black color. The lower amplitude corresponds to the light grey color. Red color defines the zones where clutter impedes a correct evaluation. black arrows mark the proposed location of the streams in historical documentation.

FIGURE 15 


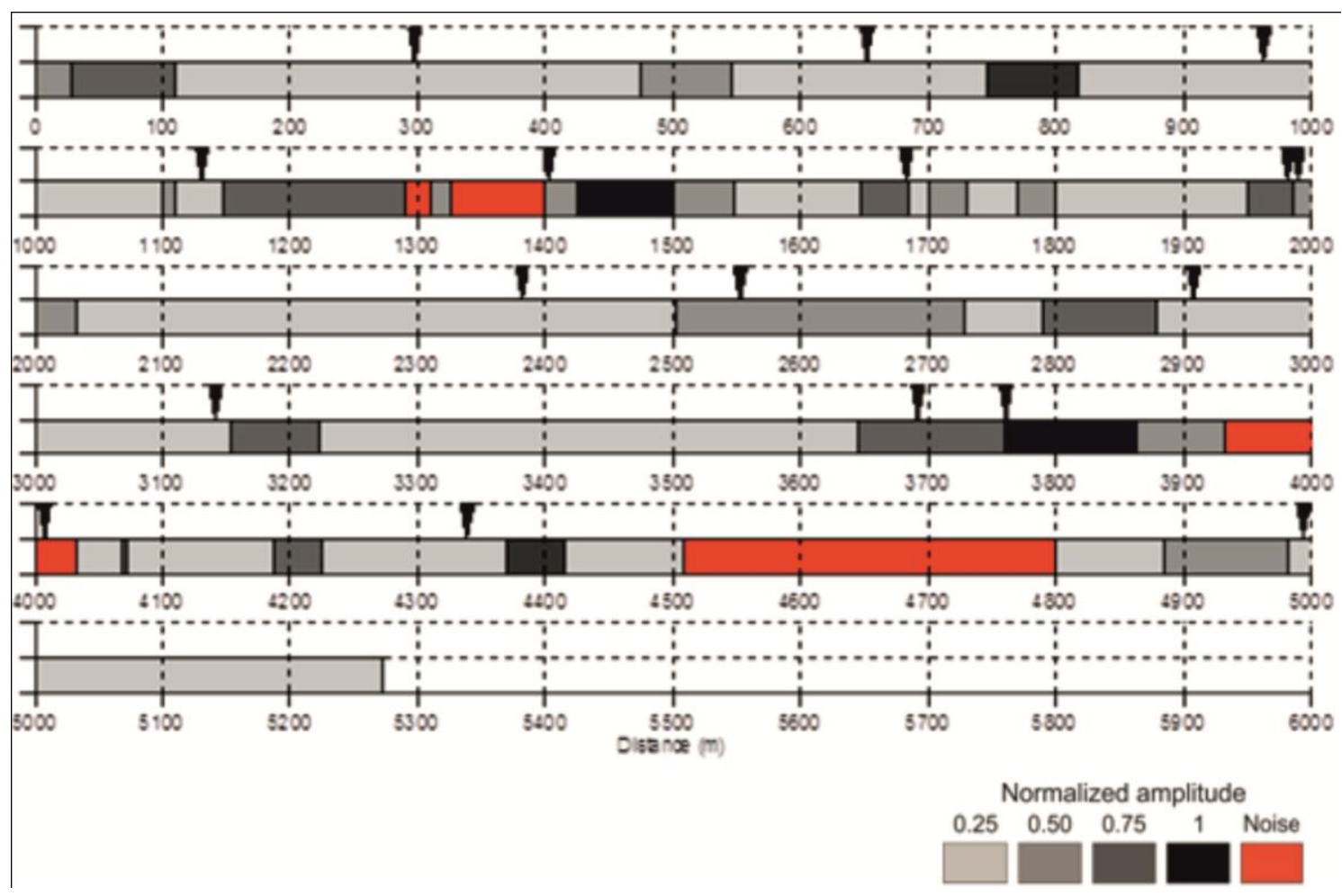

Figure 15. Results in Mallorca Street. Higher backscattering amplitude is represented in black color. The lower amplitude corresponds to the light grey color. Red color defines the zones where clutter impedes a correct evaluation. Black arrows mark the proposed location of the streams in historical documentation.

The zones characterized by high GPR backscattering amplitude were marked as more problematic sectors. There, more passive seismic measurements were required in order to define properly the soil response for the seismic zonation. Figure 16 shows the results from the two radar lines on the map of the city.

FIGURE 16 


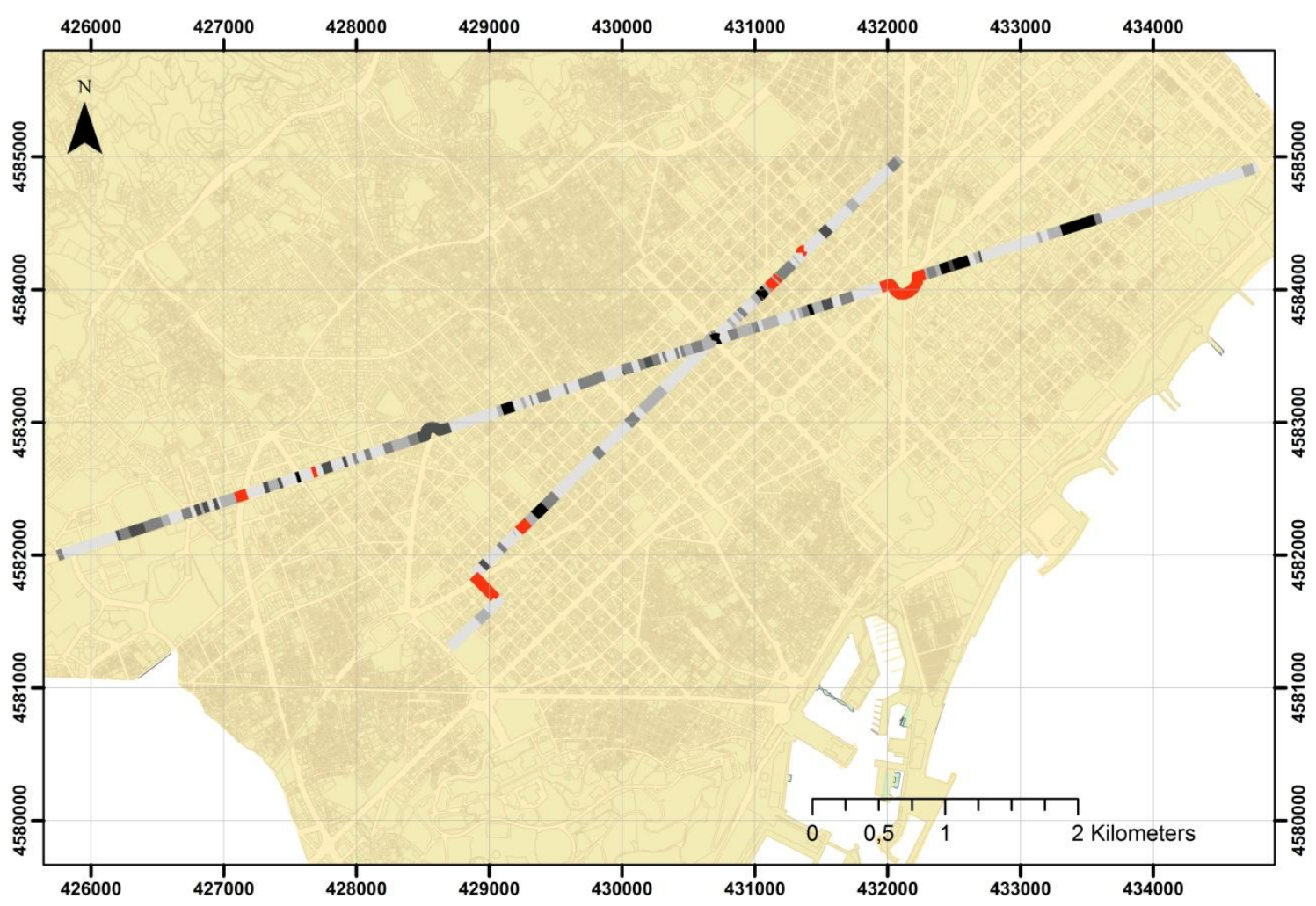

Figure 16. Map of Barcelona showing the zones that require higher density of measurement points in the seismic nanozonation (dark zones on the lines).

\section{Application to Seismic Microzonation.}

Seismic site effects are related to the changes in the soil response mainly produced by the shallow geology.

The transfer function associated to site effects can be obtained by performing techniques such as HVSR (Horizontal to Vertical Spectral Ratio), based on seismic ambient noise measurements. Maps about site effects can be further generated on the basis of this technique (e.g., Alfaro et al., 2001). The maps where the lateral soil changes are about 100 meters are described as microzonation maps. Each microzone is defined by the value of the predominant period, which is obtained averaging measurements in the microzone. Underground streams and paleochannels are sudden lateral changes in the shallow geology. Moreover, the measurements performed above or near these structures might be not representative for the entire zone.

A precise location of these geological structures helps in the selection of representative measurements points. Figure 17 presents HVSR measurements 
performed in one of the studied areas (intersection of Mallorca Street and Diagonal Avenue) allowing the identification of changes in soil response caused by the presence of subterranean water courses. The study described in this paper demonstrates that GPR is a feasible methodology to locate these subsoil structures. In the zones identified by GPR images with high random backscattering energy, the HVSR measurement points are increased. HVSR and GPR are indirect techniques, providing complementary information.

FIGURE 17
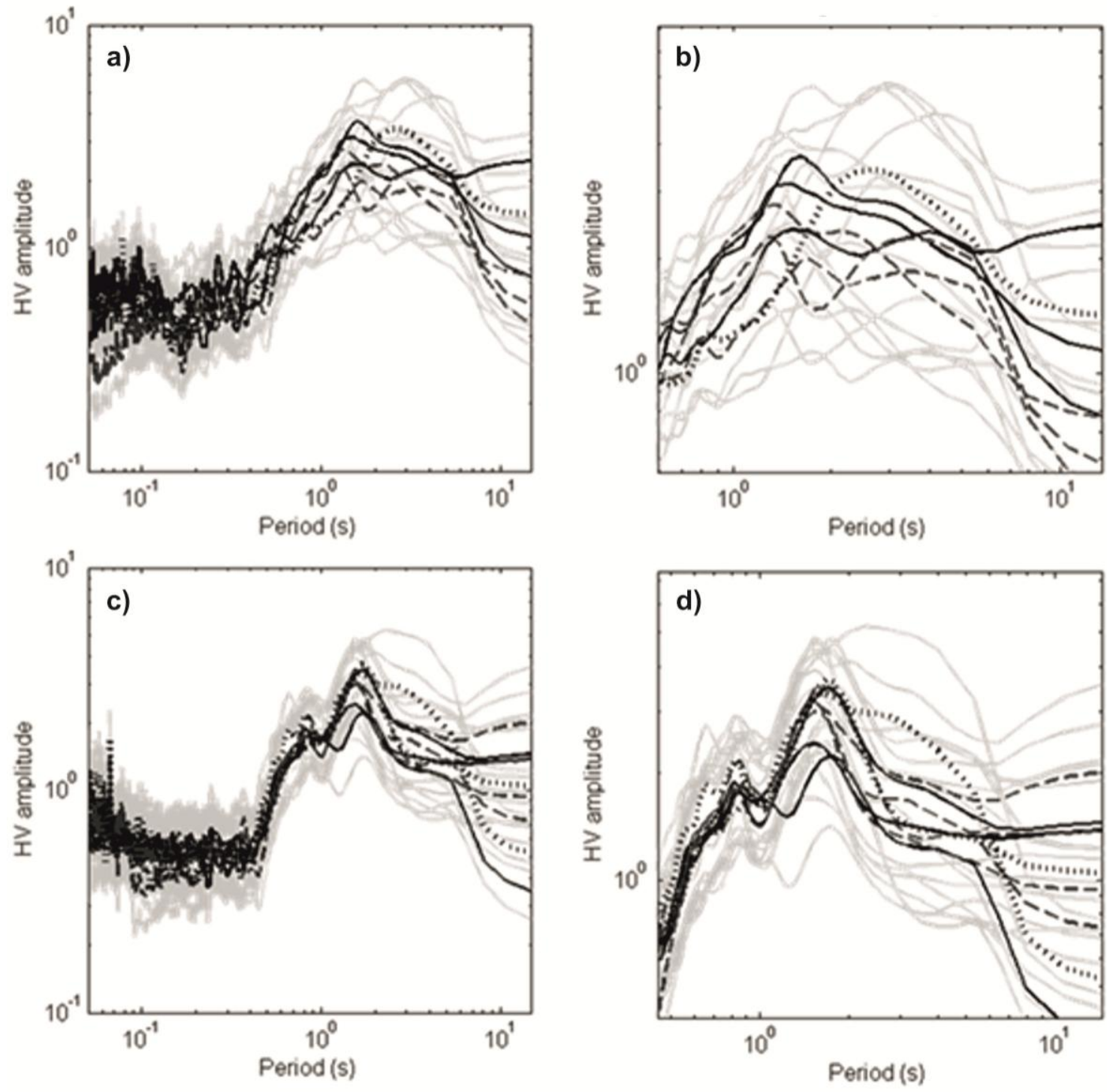

Legend 
Figure 17. a) HV amplitude. b) Peak zone detail from the measures located around the stream in Mallorca Street profile junction Balmes Street (Figure 5b). c) HV amplitude and d) Peak zone detail from the measures located around the stream in Diagonal Avenue Profile (Figure 5b).

\section{Conclusions}

This paper describes an original methodology to delineate the seismic zonation in dense cities. It is based on the backscattered energy in specific geological structures. The methodology is applied to a case study, comparing the results with complementary information.

The background noise in each GPR A-scan is analyzed in order to diminish the reflections caused by shallow targets and to define a characteristic value of noise associated to a time window. After the data analysis, the results provide values associated to each point of the B-scans. Consequently, the background noise is determined along the radar line. The main source of background noise in GPR scans is consequence of backscattering in small size targets with irregular boundary geometry. As consequence, the evaluation of the mean and maximum values of background noise allowed us to determine changes on the shallow geological materials. Therefore, underground streams and paleochannels were identified through the increase of the backscattered energy.

Some discrepancies are observed when comparing GPR results with historical and contemporary data. Notwithstanding, differences can be neglected comparing GPR results to borehole and recent excavations. Consequently, there is a good agreement between the position of the streams and paleochannels, determined by GPR backscattering analysis and direct measurements.

The most relevant discrepancies have been noticed in zones in which there is only historical and contemporary information. Therefore, in these areas there is not available information from modern surveys, including high precision measurements and standard procedures. Two sources have been identified as possible causes of this uncertainty: 
- The most extensive urban development begins in Barcelona in 1857, involving the construction of new roads and buildings. A large number of these buildings comprise underground elements (diaphragm retaining walls, basements, car parks with various levels, storm drains, rainwater tanks, bomb shelters ...). The construction of these elements could have altered the course of any underground stream.

- The old maps were developed based on different coordinates systems, not normalized and without any modern instrumental support. It is expected, therefore, that this information contains significant uncertainty in the location of the subterranean targets. This possible ambiguity suggests further comparing works, using appropriate statistical treatment to define the degree of uncertainty in the map position of the streams, allowing finally the limit of the possible affected zones by the stream bed.

Seismic passive data was also obtained in different points along the GPR lines. Minimum $\mathrm{H} / \mathrm{V}$ values appeared in the zones defined in GPR data as high backscattering zones. This result confirms the ability of GPR to delineate areas that could be associated to the same seismic soil response. This first definition of zones could be especially useful in seismic nanozonation, mainly as first evaluation previous to the ambient vibration measurements, because GPR results help in reducing their number and increases the accuracy of the final selection of nanozones.

\section{Acknowledgements}

This work has been partially funded by the Spanish Government and by the European Commission with FEDER funds, through the research project CGL2011-23621. The study is also a contribution to the EU funded COST Action TU1208, "Civil Engineering Applications of Ground Penetrating Radar".

\section{References}


Acebillo J., Folch R., 2000. Atles ambiental de l'àrea de Barcelona [Document cartogràfic]: balanç de recursos i problems. Ariel: Barcelona Regional, Barcelona.

Aibar E. and Bijker W. 1997. Constructing a city: The Cerdà plan for the extension of Barcelona. Science, Technology, \& Human Values Vol. 22, N. 1. pp. 3-30

Alfaro A., Pujades L.G., Goula X., Susagna T., Navarro M., Sanchez J., Canas J.A., 2001. Preliminary. Map of Soil's Predominant Periods In Barcelona Using Microtremors. Pure Applied Geophysics. 158, 2499-2511.

Al-Qadi I.L., Xie W., Roberts R., 2008, Scattering analysis of ground-penetrating radar data to quantify railroad ballast contamination, NDT\&E International 41, $441-447$

Anonymous (1935). Pla de la ciutat de Barcelona 1:10 000. RM 244413. (in catalan).

Arandes, R. (1998). Hidrogeología del pla de Barcelona (in catalan). Ajuntament de Barcelona, Barcelona. Spain.

Arias, P., Armesto, J., Di Capua, D., González-Drigo, R., Lorenzo, H., PerezGracia, V. 2007, Digital photogrammetry, GPR and computational analysis of structural damages in a mediaeval bridge, Engineering Failure Analysis 14, 1444-1457.

Daniels, D. J. Ground Penetrating Radar, 2nd edition. 2004. IEE Radar, Sonar and Navigation.

Greaves, R., Lesmes, D., Lee, J., and Toksöz, M.1996. Velocity variations and water content estimated from multi-offset, ground-penetrating radar. Geophysics, 61vol 3, pp 683-695. doi: 10.1190/1.1443996

IGC [2009] "Geotreball III. Mapa geologic de les zones urbanes BarcelonaHorta 1:5000," Institut Geològic de Catalunya, Barcelona (in Catalan).

IGC [2011] "Geotreball III. Mapa geologic de les zones urbanes Barcelona-Vila de Gràcia 1:5000,"Institut Geològic de Catalunya, Barcelona (in Catalan). 
Krysiński L., Sudyka J., 2013, GPR abilities in investigation of the pavement transversal cracks, Journal of Applied Geophysics 97, 27-36

Nakamura, Y. 1989. A method for dynamic characteristics estimation of subsurface using microtremor on the ground surface. Quarterly Report of the Japanese Railway Technical Research Institute (RTRI) 30 vol 1, pp 25-33.

Perez-Garcia, V., Caselles, O. ; Salinas, V. ; Pujades, L.G., Clapés, J. 2010. GPR applications in dense cities: Detection of paleochannels and infilled torrents in Barcelona GPR applications in dense cities. Proceedings of $13^{\text {th }}$ International Conference on Ground Penetrating Radar (GPR).

Perez-Garcia, V., González-Drigo, R., Sala, R. 2012, Ground-penetrating radar resolution in cultural heritage applications. Near Surface Geophysics 10, 77-87

Salinas, V., Caselles, J. O. , Pérez-Gracia, V. , S. Santos-Assunçao, J. Clapes, L. G. Pujades, R. González-Drigo, Canas, J. A. and J. Martinez-Sanchez. 2014. Nanozonation in Dense Cities: Testing a Combined Methodology in Barcelona City (Spain). Journal of Earthquake Engineering, 18:1, 90-112.

Salinas, V., Santos-Assunçao, S., Caselles, O., Pérez-Gracia, V., Pujades, L., Clapés, J., 2012, Effects on the predominant periods due to abrupt lateral soil heterogeneities, in: proceedings of the Fifthteenth World Conference on Earthquake Engineering, 24-28 September, 2012, Lisbon, Portugal, 10pp. (http://www.iitk.ac.in/nicee/wcee/article/WCEE2012_1441.pdf)

Santos-Assunçao S., Salinas V., Pérez-Gracia V., Caselles O., Pujades L.G., Clapés J., González R., Lantada N. 2014, Geological structures evaluated by means of scattering noise in Ground penetrating radar images. In: proceedings of the 15th International Conference on Ground Penetrating Radar (GPR 2014), June 30 - July,4 2014, Square Brussels Meeting Centre, Brussels, Belgium, 255-261.

Santos-Assunçao, S and Perez-Gracia, V. 2011. Mejoras en la visualización de señales de radar de subsuelos mediante el análisis frecuencial. Proceedings of Congreso español de Ensayos no destructivos. 
Santos-Assunçao, S., 2014. Ground Penetrating Radar Applications in Seismic Zonation: Assessment and Evaluation. PhD thesis. Polytechnic University of Catalonia, Barcelona-Tech.

Topp, G. C., J. L. Davis, and A. P. Annan,. 1980. Electromagnetic determination of soil water content: Measurements in coaxial transmission lines. Water Resources Research, Vol. 16, No. 3, 574582.

UPC, CLABSA, Ajuntament de Barcelona, "Estudi de les aigües subterrànies del Pla de Barcelona, Informe interno," Sector de Manteniment i Serveis, Barcelona (in Catalan). (1997).

Vazquez, L. (1861). Proyecto de ensanche de la ciudad de Barcelona y su puerto aprovado por el gobierno de S.M. (in spanish).

Ventayol, A., Palau, J., Céspedes, A., Barberá, M., Pascual, C., Roset, R., Fabrellas, I., Fernádez, J.J., Marturià, J., Cid, J., Parra, E.,Buxó, P., Cabrera, M., Galindo, J. y Bley, G. (2000). Mapa geotècnic de Barcelona 